\title{
AÇÕES COLETIVAS NO AGRONEGÓCIO: UMA ANÁLISE DO ESTADO DA ARTE A PARTIR DOS CONGRESSOS DA SOBER (2004-2013)
}

\author{
Carla Maria Schmidt* \\ Marialva Tomio** \\ Keila Raquel Wenningkamp ${ }^{* * *}$ \\ Luiz Henrique Paloschi Tomé***** \\ Ivanete Daga Cielo******
}

RESUMO: Estruturas de governança coletivas têm sido evidenciadas nas últimas décadas em diferentes áreas como, por exemplo, no agronegócio, no qual associações, cooperativas, redes, entre outras parcerias são muito encontradas. Contudo, as características dessas formas organizacionais ainda são imprecisas, denotando necessidade de estudos científicos voltados para a sua compreensão. Assim, o foco desta pesquisa é o campo das ações coletivas no agronegócio. O objetivo do estudo é compreender o estado da arte em ações coletivas no agronegócio, por meio da análise dos congressos da Sober, no período de 2004 a 2013. Para esse fim, a pesquisa está embasada a guisa da teoria de ações coletivas. Em termos metodológicos, o trabalho apresenta abordagem predominantemente quantitativa, a partir de uma pesquisa bibliométrica. A coleta de dados foi realizada a partir dos artigos publicados de 2004 a 2013 nos anais dos congressos da Sober. Os principais resultados apontam que a referida área vem se solidificando, pois um número significativo de artigos analisados versa sobre ações coletivas no contexto agroindustrial.

PALAVRAS-CHAVE: Produção científica; Ações coletivas; Sistemas agroindustriais; Sober.

\footnotetext{
Pós-doutora em Administração - FURB. Docente na Graduação em Secretariado Executivo e nos cursos de Pós-graduação stricto sensu Mestrado e Doutorado em Desenvolvimento Regional e Agronegócio e Mestrado em Ciências Ambientais - UNIOESTE. Brasil.

** Pós-doutora em Administração - UFRGS. Docente na Graduação e na Pós-graduação stricto sensu Mestrado em Administração e Doutorado em Ciências Contábeis e Administração - FURB. Brasil.

*** Doutoranda no Programa de Pós-graduação em Desenvolvimento Regional e Agronegócio (PGDRA) - UNIOESTE. Docente na Graduação em Secretariado Executivo - UNIOESTE. Brasil. E-mail: sebkeila@hotmail.com

${ }^{* * * *}$ Doutorando do Programa de Pós-graduação em Economia - UEM. Docente no Centro de Ensino Superior de Maringá (UniCesumar), na Faculdade Cidade Verde (FCV) e na Faculdade de Tecnologia do Vale do Ivaí (FATEC). Brasil.

Doutora em Desenvolvimento Regional e Agronegócio - UNIOESTE. Docente na Graduação em Secretariado Executivo - UNIOESTE, Brasil.
} 


\title{
COLLECTIVE ACTIVITY IN AGRIBUSINESS: STATE-OF-THE-ART AFTER THE SOBER CONGRESSES (2004-2013)
}

\begin{abstract}
Collective leadership structures have emerged during the last decades in different areas, such as agribusiness, in which associations, cooperatives, networks and others increased. However, the characteristics of such organizations are not well defined and require scientific investigations for in-depth information. Current analysis focuses on collective activities in agribusiness to understand the state-of-theart in collective activities in agribusiness through SOBER congresses held between 2004 and 2013. Qualitative research, coupled to a bibliometric investigation, was foregrounded on the Theory of Collective Activities. Data were retrieved from articles published between 2004 and 2013 in the Proceedings of the SOBER congresses. Results reveal that agribusiness is increasingly being established since a significant number of papers are on collective activities within the agro-industrial context.
\end{abstract}

KEY WORDS: Scientific production; Collective activity; Agro-industrial systems; SOBER congresses.

\section{INTRODUÇÃO}

Estudos científicos voltados para a compreensão de estruturas de governança coletivas ainda são considerados recentes no meio acadêmico brasileiro. Foi somente a partir do final da década de 1980 que publicações nessa área passaram a ocorrer com maior frequência, suscitando a necessidade de mais reflexões e discussões sobre a temática (AUSTIN, 2001; MÉNARD, 2004; ZYLBERSZTAJN; FARINA, 2006).

Todavia, nas últimas décadas, observa-se a tendência para o surgimento e a aplicação de ações coletivas. Acredita-se que esta ocorrência dá-se pela interconexão entre atores e firmas, que, nesta nova realidade, possuem dificuldade de sobreviver e prosperar individualmente, necessitando de cooperação (AUSTIN, 2001; MÉNARD; KLEIN, 2004). Ou seja, diferentes áreas e segmentos estão sendo envolvidos pela formação de parcerias entre indivíduos e organizações, tais como alianças estratégicas, redes, cooperações, clusters, arranjos produtivos, associações, sindicatos, entre outras. Essas parcerias significam um esforço em direção a ações 
coletivas, que surgem para atender as novas formas de relacionamento decorrentes das atuais transformações do mercado globalizado.

Nesse cenário, as ações coletivas também estão sendo visualizadas no campo do agronegócio, no qual sindicatos, associações, cooperativas, entre outras formas de parcerias são muito encontradas. Para Schmidt (2010), os Sistemas Agroindustriais (SAGs) vêm criando modelos organizacionais baseados na complementaridade e coletividade, com relacionamentos e laços de interdependência entre vários atores, apresentando-se como formas complexas de governança. Ménard e Klein (2004) também já discorriam sobre ações coletivas em SAGs citando que há crescente interesse no estudo e desenvolvimento de ações coletivas em redes agroalimentares, principalmente na Europa. Diversas novas revistas, como Supply Chain Management e Journal on Chain and Science Network têm destinado espaços consideráveis a essas questões. Isso demonstra a importância do entendimento do cenário da produção científica sobre ações coletivas no contexto agroindustrial.

Motivados por essa discussão, buscou-se analisar a produção científica nacional na área, respondendo a seguinte questão de pesquisa: como têm sido desencadeadas as pesquisas sobre ações coletivas no agronegócio? Para tanto, este estudo tem por objetivo compreender o estado da arte em ações coletivas no agronegócio, por meio da análise dos estudos publicados nos congressos da Sociedade Brasileira de Economia, Administração e Sociologia Rural (Sober), no período de 2004 a 2013.

A opção pelos congressos da Sober se deu em função desse evento ser um dos maiores e mais antigos nas áreas de economia, administração e sociologia rural, apresentando, anualmente, o resultado de pesquisas científicas desenvolvidas no agronegócio. O recorte temporal da pesquisa decorre da intensificação das discussões em torno da temática de ações coletivas após a década de 2000.

Dessa forma, acredita-se que este artigo poderá contribuir para maior compreensão sobre as formas organizacionais coletivas, apresentando o panorama atual da pesquisa científica sobre o tema. Para tanto, este estudo é composto por mais quatro partes, além desta introdução. Na parte 2 apresenta-se uma contextualização sobre ações coletivas no agronegócio. Os materiais e métodos são apresentados na parte 3. Em seguida, são discutidos os resultados encontrados sobre o cenário da 
produção científica em ações coletivas no agronegócio. Na parte 5 apresentam-se as considerações finais do estudo, as contribuições e as sugestões para pesquisas futuras na área.

\section{AÇÕES COLETIVAS NO AGRONEGÓCIO}

Para melhor compreender esta temática é essencial observar as definições e considerações conceituais que a fundamentam. Para Hardin (1997), a ação coletiva envolve a interação entre atores que almejam objetivos comuns. Consequentemente, a ação de um indivíduo pode afetar o resultado de outro e do grupo. Segundo Olson (1999), uma ação coletiva surge a partir de interesses comuns em que indivíduos planejam uma atuação coordenada para alcançá-los. Essa atuação coordenada tem origem num reconhecimento consciente de interesses comuns. Nesse sentido, conforme Brito (2001), os interesses que impulsionam uma ação coletiva decorrem de diferentes razões, entre elas: econômicas, sociais, políticas e culturais. Assim, a ligação entre atores não é originada somente por razões financeiras, mas por outros interesses, os quais não devem ser negligenciados.

Complementando, Sachs (2003) afirma que as ações coletivas podem ser concebidas por diversas formas de associativismo, tais como entidades de representação, de compra e venda, de crédito, de prospecção de vendas nos mercados externos, de controle de qualidade, entre outros. Geralmente, um grande número de pequenas empresas tem problemas para a obtenção desses aspectos, cuja superação pode ser alcançada por meio de ações coletivas.

Especificamente no agronegócio, diversos são os objetivos das ações coletivas, entre eles: obtenção de sinergias, aumento de receita, ganhos de escala e de aglomeração, redução de custos de transação, aumento do poder de barganha, diluição de riscos, redução de conflitos e maior poder de negociação (AUSTIN, 2001; SACHS, 2003; SAES, 2008; MAEDA; SAES, 2009). Outrossim, Sachs (2003) afirma que nas ações compartilhadas entre empreendimentos há a presença simultânea dos elementos concorrência e cooperação, sendo possível testemunhar sinergias extremamente benéficas para os envolvidos. Isso compreende a solução de 
problemas comuns, o aprimoramento da infraestrutura e de rede de serviços locais, a negociação com os poderes públicos locais e nacionais e a atuação conjunta para compras e vendas compartilhadas, o que proporciona maior competitividade aos integrantes da ação grupal.

Dentro desse contexto, várias são as abordagens teóricas e os modelos aplicados de ações coletivas encontradas nas organizações agroindustriais como, por exemplo: redes, supply chain systems, netchains, clusters, arranjos produtivos locais (APLs), empreendedorismo coletivo, cooperativas, sindicatos e associações (SCHMIDT; SAES, 2008; ZYLBERSZTAJN, 2010). A seguir apresentam-se os conceitos de algumas delas.

As redes ou networks, segundo Zylbersztajn e Farina (2006), são definidas como arranjos institucionais complexos, destinados à coordenação de operações multifirmas, a fim de criar e capturar valor. Esses arranjos podem ser horizontais ou verticais, envolver múltiplos agentes e períodos e, além disso, os aspectos relacionados à confiança e regras informais são potencialmente relevantes. Assim, entende-se que são formas inovadoras para obtenção de competitividade e sobrevivência no atual cenário globalizado (SCHMIDT; SAES, 2008).

Em relação à abordagem Supply Chain Management ${ }^{6}$, Zylbersztajn e Farina (1999) apontam que ela representa a evolução de duas outras teorias: a Organização Industrial e a Nova Economia Institucional (NEI), em que se estuda a cadeia como um todo (visão sistêmica) e não apenas uma transação existente no sistema. Já o conceito de netchain foi desenvolvido por Lazzarini, Chaddad e Cook (2001), integrando as abordagens networks e supply chain. Sendo assim, trata-se de um conjunto de redes, composto por laços horizontais dentro de um mesmo setor ou grupo (mesma camada) e, laços verticais entre organizações de setores diferentes (diferentes camadas).

No que se refere aos clusters, também conhecidos por aglomerados, esses são conceituados por Porter (1999, p. 211) como "um agrupamento geograficamente concentrado de empresas inter-relacionadas e instituições correlatas numa determinada área, vinculadas por elementos comuns e complementares". Ainda segundo esse autor, eles podem ser encontrados em economias grandes e pequenas, em áreas rurais e urbanas, bem como em regiões metropolitanas e cidades.

Gestão da Cadeia de Suprimento 
Por sua vez, os arranjos produtivos locais são aglomerações territoriais de agentes econômicos, políticos e sociais, que estão localizados em um mesmo território. Além disso, desenvolvem atividades econômicas correlatas e demonstram vínculos expressivos de produção, interação, cooperação e aprendizagem. Sendo assim, os APLs referem-se a inovadoras formas de atuação, cujo objetivo é auxiliar para uma produção mais eficiente, agregando valor aos agentes envolvidos (REDESIT, 2014).

Com base nas definições expostas, percebe-se que, embora existam nomenclaturas diferenciadas para se referir as abordagens e modelos aplicados de ações coletivas, estes apresentam características muito semelhantes entre si. De maneira geral, os modelos priorizam transações entre agentes ou organizações com laços de interdependência entre si, baseando-se na complementaridade e na coletividade. Assim, após uma breve apresentação sobre as abordagens teóricas e os modelos aplicáveis de ações coletivas em SAGs, apresenta-se, a seguir, o item sobre material e métodos utilizados nesta pesquisa.

\section{MATERIAL E MÉTODOS}

Para o desenvolvimento deste estudo, utilizou-se o método de pesquisa bibliométrico, de preeminência quantitativa, e, também, a abordagem qualitativa, por meio da análise de conteúdo. Entende-se que o estudo bibliométrico é de caráter quantitativo, pois é caracterizado pelo uso de métodos e técnicas quantitativas e estatísticas na análise da produção e disseminação do conhecimento. Isso a fim de identificar padrões de comportamento na produção e reprodução de informações (MACIAS-CHAPULA, 1998; VANTI, 2002).

O objeto de investigação deste estudo refere-se aos trabalhos publicados nos anais dos congressos da Sober, no período de 2004 a 2013. Essa escolha não foi aleatória, uma vez que esse evento (com mais de 50 anos de existência) é referência nacional em publicações relacionadas ao meio rural e congrega um quantitativo bibliográfico expressivo sobre o agronegócio.

Em relação aos artigos consultados no período, ressalta-se que só foram 
considerados os trabalhos completos, de forma que pôsteres e painéis não fizeram parte do estudo. Dessa forma, para o total publicado nos dez anos (7.826 artigos), aplicou-se a técnica de análise de conteúdo para selecionar trabalhos na temática de ações coletivas. Por serem as ações coletivas formas muito abrangentes, complexas e confusas, cujas características ainda não são completamente conhecidas (MÉNARD, 2004), a análise realizada foi por meio de leitura e interpretação de texto, e não unicamente por busca em palavras-chave.

Desse modo, para a seleção dos artigos específicos de ações coletivas, foram consideradas as diferentes abordagens e modelos aplicáveis, tais como: redes/networks, supply chain systems, netchain, clusters, APL, empreendedorismo coletivo, cooperativas, sindicatos e associações. Após a etapa de seleção, foram encontrados 488 artigos correspondentes a estudos sobre ações coletivas.

Depois dessa coleta inicial, realizaram-se diversas análises. A primeira foi a distribuição dos artigos por grupo de trabalho (GT). Posteriormente, dividiramse os artigos entre trabalhos teóricos, empíricos e teórico-empíricos, em que nos trabalhos denominados "teóricos" enquadram-se somente os que possuíam em seu corpus teórico alguma das abordagens de ações coletivas e que não apresentaram estudos empíricos; por sua vez, os trabalhos "empíricos" envolveram os que só tinham pesquisa de campo; já os "teórico-empíricos" integram as duas análises.

O terceiro procedimento foi a análise da abordagem teórica e do modelo aplicado de ações coletivas. Nesse caso, apontou-se o tipo de teoria utilizada como referência e, além disso, o modelo aplicado para o caso dos estudos empíricos (redes/networks, supply chain systems, netchain, clusters, APL, empreendedorismo coletivo, cooperativas, sindicatos e associações).

Após as etapas já descritas, identificaram-se outros aspectos, tais como os tipos de SAGs e a localização geográfica dos estudos empíricos (com auxílio do software TerraView); a abordagem metodológica utilizada; a identificação de autorias e coautorias; as publicações interinstitucionais e, as instituições que tiveram mais trabalhos publicados.

Ressalta-se que alguns artigos analisados não possuíam todas as informações necessárias às análises. Em decorrência disso, ao longo das discussões criou-se a categoria "Não informado", a exemplo de 2004, quando os trabalhos não tinham informações relativas aos GTs e instituições. 


\section{RESULTADOS E DISCUSSÃO}

Os resultados apresentados neste capítulo ilustram o desencadeamento da produção científica em ações coletivas no agronegócio, desenvolvida nos congressos da Sober, no período 2004 a 2013.

Primeiramente, buscou-se analisar o número de artigos publicados ao longo dos últimos dez anos nos congressos da Sober e, ainda, compreender se essa comunidade científica tem desenvolvido estudos sobre ações coletivas no agronegócio. Esse resultado pode ser visualizado no Gráfico 1.

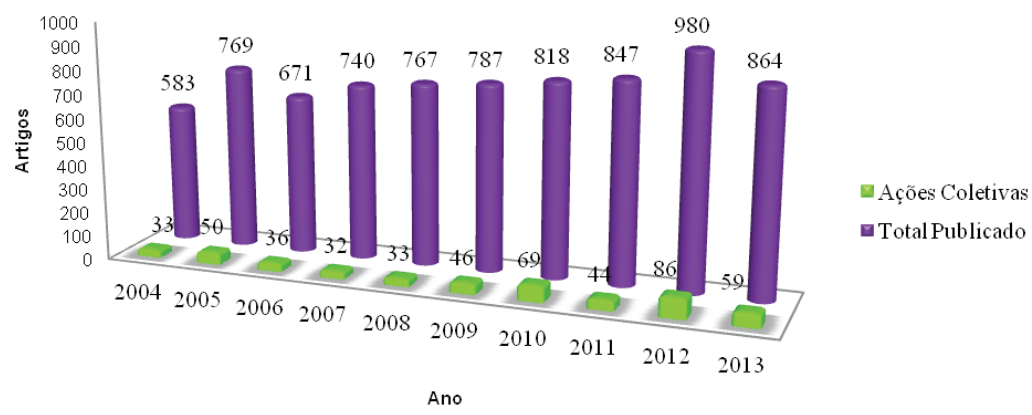

Gráfico 1. Quantidade de artigos publicados por ano (total e específicos) Fonte: Dados da pesquisa.

Os dados coletados demonstram que de 2004 a 2013 foram publicados 7.826 artigos nos congressos da Sober, e que, deste total, 488 (6,2\%) correspondem a estudos sobre ações coletivas no agronegócio. Numa análise preliminar, o percentual de artigos sobre ações coletivas pode não se apresentar tão significativo em relação ao total de artigos do congresso. Contudo, considerando a diversidade de temáticas a serem trabalhadas na perspectiva do meio rural brasileiro, em áreas como economia, administração e sociologia, entende-se que o tema de ações coletivas tem considerável participação nas publicações da Sober. Vale dizer que esta tendência tem sido discutida por autores como Grandori e Soda (1995), Economides 
(1996) e Sauvée (2002), os quais reconhecem o estudo de estruturas complexas como fenômeno-chave na economia moderna, principalmente em estudos da área de SAGs, sendo fundamental compreender as bases desses modelos organizacionais.

No que tange à distribuição desses artigos por ano (2004-2013), não foram evidenciadas diferenças significativas, apenas um número relativamente maior para os anos 2010 e 2012 (respectivamente, 8,4\% e 8,8\%). Na sequência, teve-se o intuito de descrever o campo de estudo dos artigos, destacando a participação deles nos respectivos grupos de trabalho (GTs), que compuseram as edições do evento em análise, conforme demonstrado na Tabela 1 .

Tabela 1. Quantidade de artigos publicados por Grupo de Trabalho (GT)

\begin{tabular}{lcc}
\hline \multicolumn{1}{c}{ Grupo de trabalho } & Total & Participação \\
\hline Instituições e desenvolvimento social na agricultura e agroindústria & 72 & $14,8 \%$ \\
Economia e gestão do agronegócio & 64 & $13,1 \%$ \\
Estrutura, evolução e dinâmica dos sistemas agroalimentares e cadeias & 53 & $10,9 \%$ \\
agroindustriais & 50 & $10,2 \%$ \\
Agricultura familiar e ruralidade & 50 & $10,2 \%$ \\
Desenvolvimento rural, territorial e regional & 49 & $10,0 \%$ \\
Instituições e organizações na agricultura & 21 & $4,3 \%$ \\
Administração rural e gestão do agronegócio & 21 & $4,3 \%$ \\
Agropecuária, meio ambiente e desenvolvimento sustentável & 16 & $3,3 \%$ \\
Sistemas agroalimentares e cadeias agroindustriais & 12 & $2,5 \%$ \\
Comercialização, mercados e preços agrícolas & 11 & $2,3 \%$ \\
Ciência, pesquisa e transferência de tecnologia & 10 & $2,0 \%$ \\
Políticas sociais para o campo & 6 & $1,2 \%$ \\
Evolução e estrutura da agropecuária no Brasil & 5 & $1,0 \%$ \\
Socioeconomia solidária e desenvolvimento local & 41 & $8,4 \%$ \\
Comércio internacional & 488 & $\mathbf{1 0 0} \%$ \\
Reforma agrária, mercado de terras, políticas sociais na agricultura & 2 & $0,4 \%$ \\
Associativismo no meio rural & 1 & $0,2 \%$ \\
Não informado & $41 \%$ \\
\hline & &
\end{tabular}

Fonte: Dados da pesquisa. 
Ações coletivas no Agronegócio: uma análise do estado da arte a partir dos congressos da...

Ao analisar os resultados da Tabela 1 é possível inferir que a temática de ações coletivas se faz presente em uma parcela significativa da totalidade dos Grupos de Trabalhos (17 GTs). Cabe destacar que houve maior incidência de artigos em GTs que discutem questões emergentes do agronegócio, a exemplo de instituições, desenvolvimento social e rural, gestão do agronegócio, dinâmica dos sistemas agroalimentares e agricultura familiar, fato que pode ser justificado pelo próprio caráter emergente da temática de ações coletivas. Em relação ao item "Não Informado", o mesmo é reflexo dos anos de 2004, 2005, 2009 e 2011, nos quais 41 artigos publicados nos anais não apresentavam a informação relativa ao GT.

Após as análises preliminares do primeiro bloco, apresentam-se, na sequência (Tabela 2), dados referentes a aspectos teóricos e empíricos identificados nos artigos.

Tabela 2. Quantidade de artigos teóricos x empírico

\begin{tabular}{lcccccccccccc}
\hline Ano & 2004 & 2005 & 2006 & 2007 & 2008 & 2009 & 2010 & 2011 & 2012 & 2013 & Total & Part. \\
\hline Teórico & 6 & 6 & 6 & 2 & 1 & 2 & 5 & 1 & 7 & 1 & 37 & $7,6 \%$ \\
Empírico & 14 & 19 & 19 & 13 & 14 & 14 & 30 & 21 & 42 & 24 & 210 & $43,0 \%$ \\
$\begin{array}{l}\text { Teórico- } \\
\text { empírico }\end{array}$ & 13 & 25 & 11 & 17 & 18 & 30 & 34 & 22 & 37 & 34 & 241 & $49,4 \%$ \\
\hline Total & 33 & 50 & 36 & 32 & 33 & 46 & 69 & 44 & 86 & 59 & 488 & $100 \%$ \\
\hline
\end{tabular}

Fonte: Dados da pesquisa

Os resultados apontam que, do total de 488 artigos sobre ações coletivas, $241(49,4 \%)$ possuem suporte teórico e discutem a temática em questão a partir de análises empíricas. Além disso, 210 (43\%) possuem somente análise empírica e outros 37 (7,6\%) desenvolvem unicamente estudos teóricos. Pela recente discussão do tema, conforme o esperado, poucos estudos se dedicam exclusivamente a análises teóricas, uma vez que essas geralmente demandam maior dedicação analítica por parte dos pesquisadores, maior conhecimento e profundidade crítica dos temas.

Observa-se, ainda, que 43\% de artigos não apresentam nenhuma forma de argumentação teórica voltada às ações coletivas. Assim, apesar desses trabalhos muitas vezes apresentarem estudos de casos relevantes, pode-se dizer que eles 
poderiam contribuir mais para o avanço teórico-científico da área, caso envolvessem referenciais teóricos sobre ações coletivas, questão que pode ser objeto de reflexão dos pesquisadores da área.

Dando continuidade às discussões sobre os aspectos teóricos dos estudos, buscou-se aprofundar a investigação sobre o teor da revisão de literatura desenvolvida nos trabalhos. Especificamente, teve-se o intuito de analisar se os pesquisadores discorrem sobre a teoria de ação coletiva ou de grupos propriamente dita, ou se discorrem sobre alguma abordagem possível dentro da temática de ações coletivas, como as anteriormente apontadas no referencial teórico (redes, clusters, arranjos produtivos, associações, cooperativas, entre outras). Os resultados dessa investigação são apresentados no Gráfico 2.

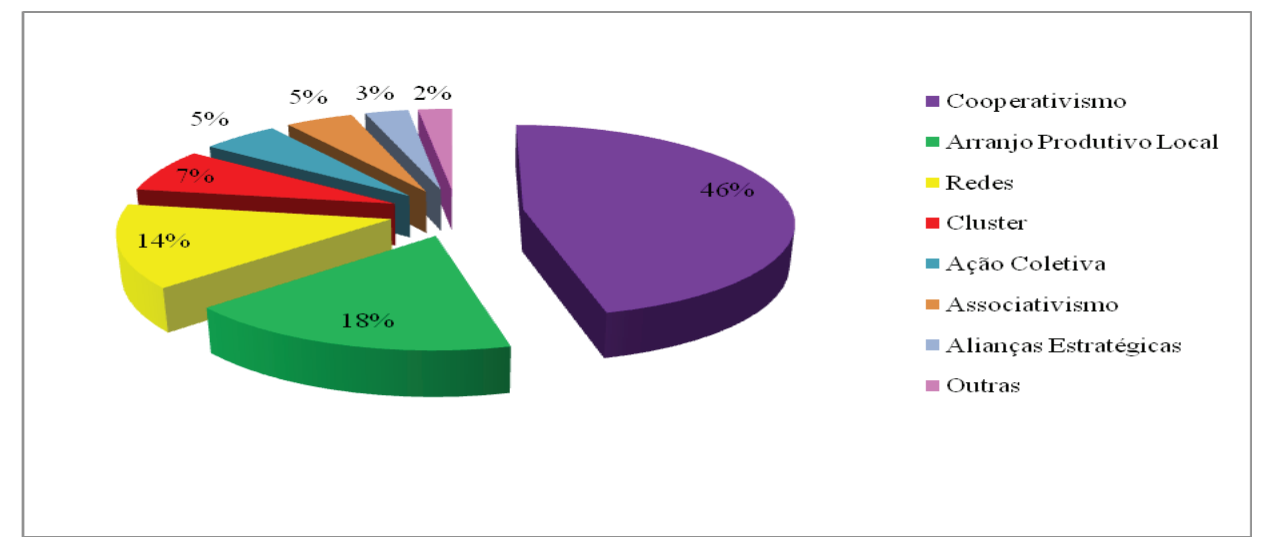

Gráfico 2. Abordagens teóricas utilizadas nos artigos

Fonte: dados da pesquisa.

Os resultados demonstram que poucas investigações ocorrem no campo específico da teoria de ação coletiva ou de grupo (apenas 5\%), ou seja, uma minoria de estudos se debruça de forma aprofundada sobre a essência da teoria. A grande maioria dos artigos discorre sobre alguma abordagem relacionada à coletividade. Isso pode ser justificado em função do alto índice de estudos empíricos existentes, para os quais as abordagens, provavelmente, respondem de forma satisfatória aos achados empíricos.

Além disso, observa-se que, dentre as abordagens encontradas nos estudos, houve um significativo destaque para o cooperativismo (46\%). Além desse, arranjos 
produtivos locais e redes também se destacaram, tendo esses sido referenciados como suporte teórico para $18 \%$ e $14 \%$ dos artigos analisados, respectivamente. $\mathrm{O}$ Gráfico 2 também permite visualizar que outras abordagens foram utilizadas como suporte teórico para os artigos, quais sejam: cluster, associativismo, aliança e outros (sindicalismo, netchain e supply chain). De maneira geral, acredita-se que todas as abordagens, em maior ou menor grau, são utilizadas nos artigos porque conseguem representar um suporte teórico para as pesquisas de campo realizadas.

Outra investigação realizada no estudo se refere ao modelo de ação coletiva encontrado como objeto de investigação. Buscou-se compreender quais as formas aplicadas de ação coletiva que serviram como objeto de pesquisas de campo. Os resultados podem ser visualizados no Gráfico 3.

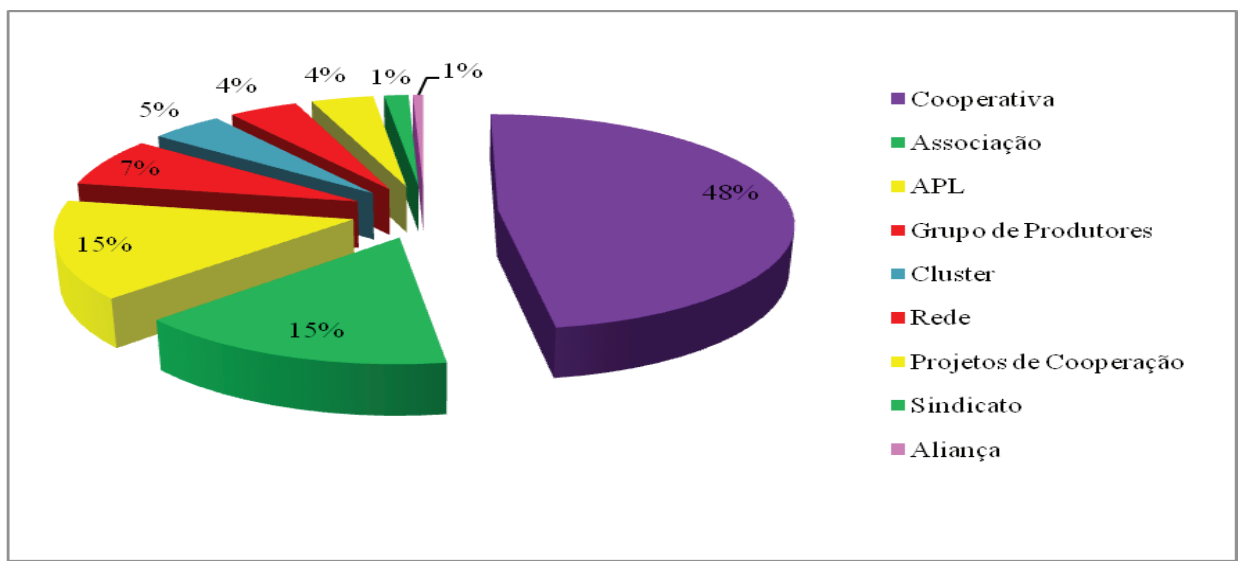

Gráfico 3. Modelos aplicados de ação coletiva Fonte: Dados da pesquisa.

Primeiramente, é importante destacar que, em conformidade com a teoria (Sauvée, 2002; Zylbersztajn, 2010), os modelos de ação coletiva são fortemente encontrados no agronegócio brasileiro, uma vez que representam o objeto de investigação de 451 estudos. Conforme o Gráfico 3, de 2004 a 2013, nove modelos diferentes foram encontrados e estudados, o que demonstra uma diversidade de formas coletivas nos diferentes sistemas agroindustriais do Brasil.

Nesse aspecto, conforme o esperado, os resultados encontrados para os objetos de investigação (modelos organizacionais) pouco diferem dos resultados 
teóricos apresentados anteriormente, no Gráfico 2. Nos achados empíricos, novamente as cooperativas aparecem de forma evidente (48\%), seguidas das associações e dos arranjos produtivos locais, ambos encontrados em $15 \%$ dos estudos. No que tange às associações, vale dizer que existe incompatibilidade em relação ao resultado anterior, no qual o associativismo foi suporte teórico para apenas 5\% dos estudos. Por outro lado, entende-se que a similaridade e a complementaridade das abordagens teóricas podem justificar tal resultado.

Outra análise realizada foi a identificação dos segmentos mais estudados nos artigos (Tabela 3), a fim de compreender em quais sistemas agroindustriais as ações coletivas se tornam mais evidentes.

Tabela 3. SAGs/segmentos mais representativos

\begin{tabular}{lcc}
\hline SAG/Segmento & Quantidade & Participação \\
\hline Leite & 61 & $12,4 \%$ \\
Fruticultura & 48 & $9,8 \%$ \\
Grãos & 41 & $8,4 \%$ \\
Pecuária & 35 & $7,1 \%$ \\
Crédito rural & 27 & $5,5 \%$ \\
Vitivinícola & 14 & $2,9 \%$ \\
Horticultura & 13 & $2,7 \%$ \\
Piscicultura & 11 & $2,2 \%$ \\
Orgânicos & 10 & $2,0 \%$ \\
Outros & 69 & $14,1 \%$ \\
Não Informado & 161 & $32,9 \%$ \\
& & \\
\hline Total & 490 & $\mathbf{1 0 0} \%$ \\
\hline
\end{tabular}

Fonte: Dados da pesquisa.

Conforme a Tabela 3, os SAGs do leite, de frutas e de grãos foram os que apareceram com maior frequência entre os estudos realizados. Assim, entende-se que, apesar da existência de inúmeras políticas públicas de fomento, a pesquisa 
no âmbito de pequenas propriedades, os SAGs mais tradicionais no mercado continuam sendo os de maior interesse de investigação. Isso se deve, possivelmente, pela facilidade de acesso a bancos de dados estruturados nesses segmentos, além da visibilidade existente nesses setores. Além disso, a informalidade, muitas vezes presente nas atividades desenvolvidas por pequenos agricultores familiares dificulta o acesso a informações de pesquisa e demanda maior disponibilidade de tempo e recurso por parte dos pesquisadores.

$\mathrm{Na}$ sequência, teve-se o intuito de mapear a localização geográfica dos objetos de análise empírica (Gráfico 1), ou seja, dos modelos de ação coletiva apresentados nos estudos.

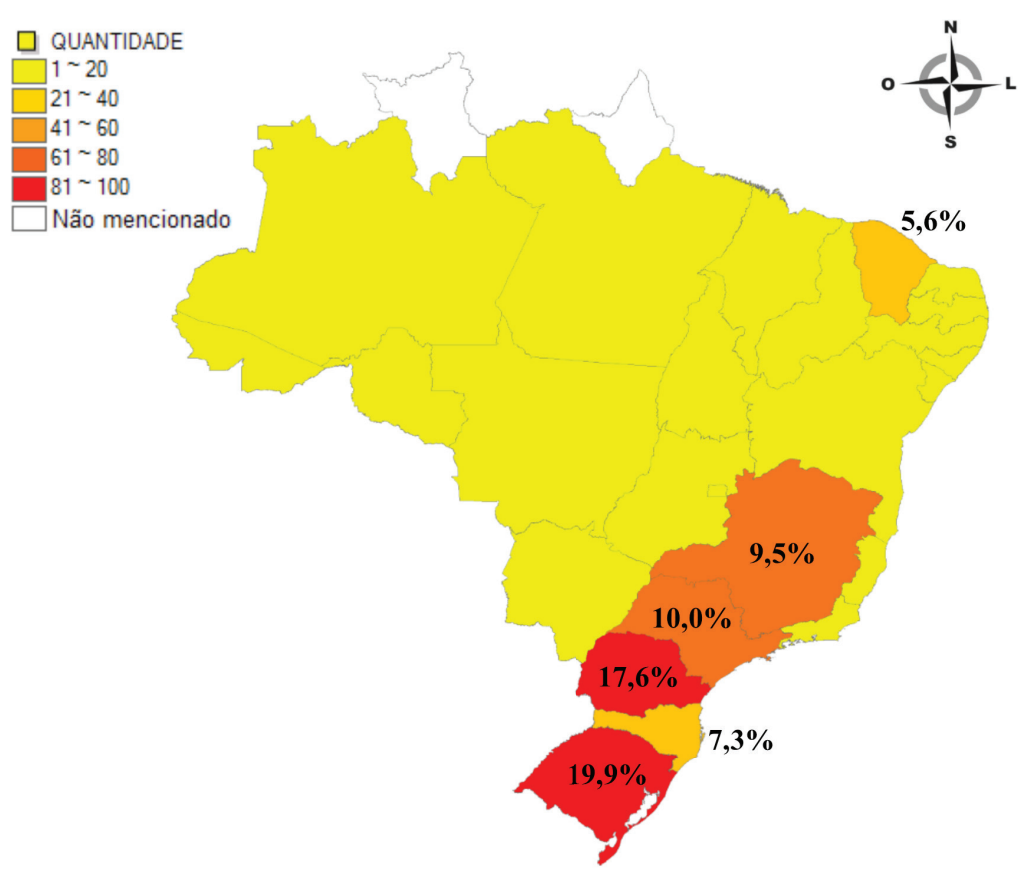

Figura 1. Mapa da localização geográfica dos modelos aplicados nos estudos empíricos Fonte: dados da pesquisa.

Considerando que o congresso da Sober possui abrangência nacional e, ainda, que as ações coletivas são reconhecidas pela literatura econômica como mecanismos de desenvolvimento para pequenos produtores rurais nas mais 
distintas regiões, esperava-se encontrar homogeneidade de distribuição espacial no que tange aos objetos de análise empírica. Contudo, o resultado (que pode ser visualizado na Figura 1) aponta para forte concentração geográfica na região Sul do país (Rio Grande do Sul - 19,9\%; Paraná - 17,6\%; Santa Catarina - 7,3\%), a qual representa $44,8 \%$ do total dos objetos de pesquisa analisados. Esse cenário pode estar associado às características culturais cooperativistas da população sulista, por ser formada em grande maioria por imigrantes europeus, uma vez que a Europa representa o berço do cooperativismo (PINHO, 1966; SILVA NETO et al., 2000).

Além desses, somente os Estados de São Paulo, Minas Gerais e Ceará também apresentaram percentual significativo, o que leva a refletir sobre a necessidade de expansão da temática de ações coletivas como área de interesse para os demais Estados e regiões do país, onde há baixa incidência de estudos.

No terceiro bloco de investigações, o interesse recai sobre os aspectos metodológicos dos artigos. Para tanto, analisou-se primeiramente qual o tipo de abordagem metodológica utilizada pelos autores. Esse resultado pode ser visualizado na Tabela 4 .

Tabela 4. Abordagens metodológicas utilizadas nos artigos

\begin{tabular}{lcccccccccccc}
\hline \multicolumn{1}{c}{ Ano } & 2004 & 2005 & 2006 & 2007 & 2008 & 2009 & 2010 & 2011 & 2012 & 2013 & Total & Part. \\
\hline Não informado & 24 & 42 & 25 & 23 & 22 & 31 & 38 & 25 & 43 & 23 & 296 & $60,6 \%$ \\
Qualitativa & 8 & 4 & 8 & 8 & 6 & 9 & 18 & 11 & 19 & 21 & 112 & $23,0 \%$ \\
$\begin{array}{l}\text { Qualitativa- } \\
\text { quantitativa }\end{array}$ & 1 & 3 & 3 & 1 & 5 & 6 & 12 & 5 & 14 & 13 & 63 & $12,9 \%$ \\
Quantitativa & 0 & 1 & 0 & 0 & 0 & 0 & 1 & 3 & 10 & 2 & 17 & $3,5 \%$ \\
\hline Total & 33 & $\mathbf{5 0}$ & 36 & $\mathbf{3 2}$ & $\mathbf{3 3}$ & $\mathbf{4 6}$ & $\mathbf{6 9}$ & $\mathbf{4 4}$ & $\mathbf{8 6}$ & $\mathbf{5 9}$ & $\mathbf{4 8 8}$ & $\mathbf{1 0 0 \%}$ \\
\hline
\end{tabular}

Fonte: Dados da pesquisa.

Ao observar os dados, constatou-se forte incidência de artigos com abordagem qualitativa (23\%). Isto pode ser justificado pela natureza dos estudos da área, os quais se utilizam com frequência de estudos de caso para exploração empírica. Outra constatação que merece destaque se refere aos estudos que não informam claramente no seu escopo metodológico a abordagem utilizada, os quais 
totalizam $60 \%$ dos artigos analisados. Cabe destacar que a clareza metodológica é fundamental para o processo evolutivo de uma área em termos científicos, havendo, assim, necessidade de maior atenção dos pesquisadores no que tange ao rigor metodológico.

Posterior à abordagem metodológica, analisou-se a constituição de autoria dos artigos, se individualmente ou em equipe. Especificamente, pretendeuse investigar a representatividade dos artigos escritos sob o regime de coautoria, uma vez que tais produções se apresentam como positivas para o incremento da produção científica, porque normalmente envolvem grupos de pesquisa, o que pode ser visualizado na Tabela 5.

Tabela 5. Quantidade de autores por artigo

\begin{tabular}{lccccccccccc}
\hline \multicolumn{1}{c}{$\begin{array}{c}\text { Ano } \\
\text { Autorias }\end{array}$} & 2004 & 2005 & 2006 & 2007 & 2008 & 2009 & 2010 & 2011 & 2012 & 2013 & Total \\
\hline 1 autor & 2 & 10 & 5 & 2 & 1 & 3 & 3 & 1 & 4 & 1 & 32 \\
2 autores & 16 & 17 & 11 & 10 & 10 & 18 & 25 & 14 & 27 & 16 & 164 \\
$\begin{array}{l}3 \text { autores ou } \\
\text { mais }\end{array}$ & 13 & 22 & 20 & 20 & 22 & 24 & 41 & 28 & 55 & 42 & 287 \\
Não informado & 2 & 1 & 0 & 0 & 0 & 1 & 0 & 1 & 0 & 0 & 5 \\
\hline Total & 33 & $\mathbf{5 0}$ & 36 & $\mathbf{3 2}$ & $\mathbf{3 3}$ & $\mathbf{4 6}$ & $\mathbf{6 9}$ & $\mathbf{4 4}$ & $\mathbf{8 6}$ & $\mathbf{5 9}$ & 488 \\
\hline
\end{tabular}

Fonte: dados da pesquisa.

Os dados demonstram que a maioria dos artigos $(58,8 \%)$ foi elaborada por equipes de trabalho formadas por três ou mais autores. Além disso, 33,6\% foram elaborados por pares e apenas $6,6 \%$ dos artigos foram desenvolvidos individualmente. Esse resultado aponta para a confirmação de uma tendência no âmbito das pesquisas acadêmico-científicas, quer seja, a elaboração de estudos a partir da perspectiva do trabalho colaborativo entre pesquisadores. Nesse sentido, Bulgacov e Verdu (2001) afirmam que a realização de estudos em parceria com outros pesquisadores reduz as distâncias para o ingresso nas esferas internacionais de publicação e aumenta o número de pesquisas desenvolvidas.

Em continuidade à investigação referente às equipes de elaboração dos artigos, procurou-se identificar a origem institucional dos autores. Nesse quesito, 
observou-se que pesquisadores advindos de 646 instituições foram responsáveis pelo desenvolvimento dos 488 artigos encontrados nos dez anos de estudos da comunidade soberiana em congressos. Isso remete ao entendimento de que houve trabalhos interinstitucionais, aspecto considerado positivo na comunidade científica, em função da troca de informações existentes nos trabalhos entre diferentes grupos e instituições. Dentre o total de instituições encontradas, na Tabela 6 estão apresentadas as que tiveram maior incidência nas publicações, especificamente as que apresentaram acima de $2 \%$ de participação.

Tabela 6. Origem institucional dos autores

\begin{tabular}{lcc}
\hline \multicolumn{1}{c}{ Instituição } & Quantidade & Participação \\
\hline Universidade Federal do Rio Grande do Sul - UFRGS & 58 & $9,0 \%$ \\
Universidade Federal de Santa Maria - UFSM & 38 & $5,9 \%$ \\
Universidade Federal de Viçosa - UFV & 34 & $5,3 \%$ \\
Universidade Estadual do Oeste do Paraná - Unioeste & 22 & $3,4 \%$ \\
Universidade de São Paulo - USP & 21 & $3,3 \%$ \\
Embrapa & 21 & $3,3 \%$ \\
Universidade Paranaense - Unipar & 19 & $2,9 \%$ \\
Universidade Federal do Ceará - UFC & 17 & $2,6 \%$ \\
Universidade Federal de Santa Catarina - UFSC & 15 & $2,3 \%$ \\
Universidade de Brasília - UnB & 15 & $2,3 \%$ \\
Universidade Federal de Mato Grosso do Sul - UFMS & 14 & $2,2 \%$ \\
Universidade Estadual Paulista - Unesp & 14 & $2,2 \%$ \\
Universidade Federal de Rondônia - Unir & 14 & $2,2 \%$ \\
\hline Demais & 344 & $\mathbf{5 3 , 3} \%$ \\
\hline
\end{tabular}

Fonte: Dados da pesquisa.

Os dados demonstram que as duas instituições com maior participação $(14,9 \%)$ estão geograficamente situadas no Estado do Rio Grande do Sul. Além disso, vale dizer que $23,5 \%$ dos artigos foram desenvolvidos por instituições localizadas na região Sul. Esse resultado pode ser decorrente da alta concentração de modelos 
organizacionais coletivos identificados naquela região, conforme discutido anteriormente e apresentados na Figura 1.

Por fim, considerando o fato da existência de trabalhos interinstitucionais, buscou-se mensurar este resultado ao longo do período estudado, conforme visualizado no Gráfico 4. Cabe destacar que no ano de 2004 não houve identificação institucional dos autores nos artigos, impossibilitando a análise naquele período.

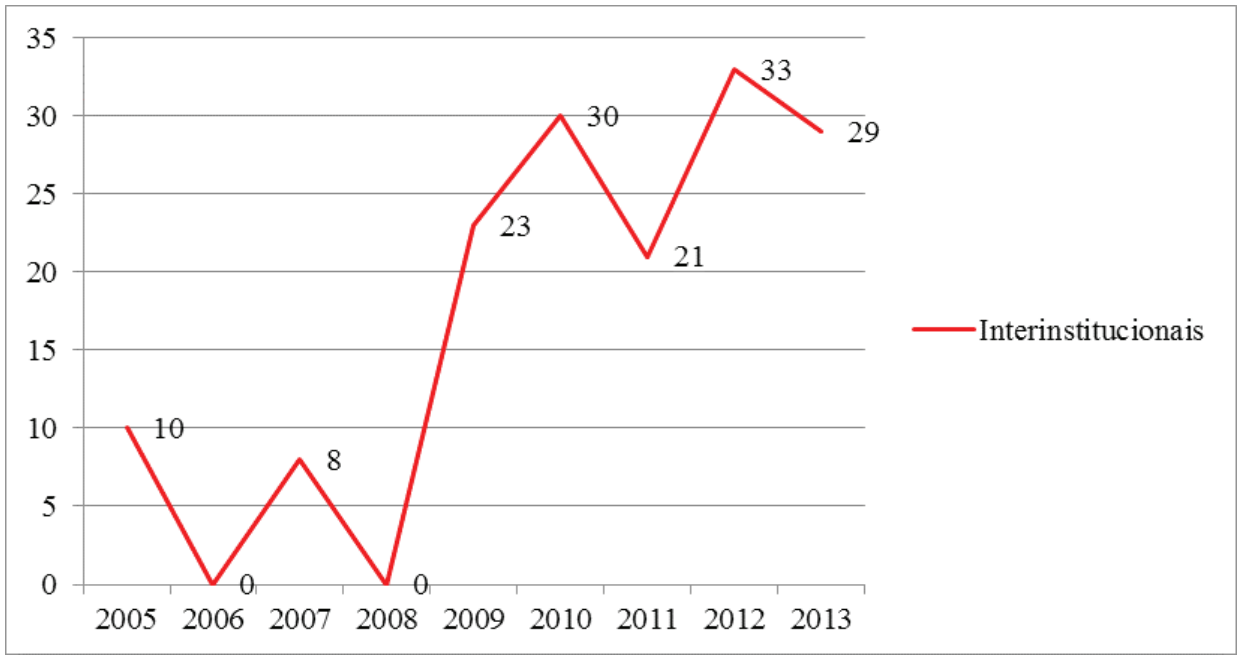

Gráfico 4. Presença de pesquisadores interinstitucionais

Fonte: Dados da pesquisa.

Como já dito, dado o caráter recente de exploração da temática de ações coletivas em agribusiness no Brasil, pode-se ressaltar que houve avanços consideráveis na formação de grupos de pesquisadores interinstitucionais nessa direção. Isso porque, no início do período analisado (2005 a 2008), as pesquisas com essa particularidade atingiam índice inferior (11,7\%) e, a partir de 2009, essas passaram a representar $88,3 \%$. Possivelmente, essa mudança de cenário é em decorrência de interesses comuns entre pesquisadores, preocupados não apenas no avanço quantitativo como em aspectos qualitativos da área. Além disso, as novas formas de comunicação advindas das tecnologias digitais também facilitam o trabalho partilhado e a constituição de grupos de pesquisas, que, sem o aparato tecnológico, ficariam comprometidos pelas distâncias geográficas. Nesse sentido, os avanços da 
pesquisa na área de ações coletivas, principalmente com o desenvolvimento, mesmo que embrionário, de um trabalho em rede de pesquisadores, parece apontar para maior solidificação e fortalecimento de linhas de pesquisa em ações coletivas.

\section{CONSIDERAÇÕES FINAIS}

As formas organizacionais coletivas, apesar de muito atuantes dentro do contexto agroindustrial, ainda precisam ser mais exploradas, fato que motivou o desenvolvimento deste estudo. Assim, esta pesquisa contribuiu com a discussão em torno dos modelos organizacionais coletivos no agronegócio, a partir de um levantamento sobre a produção científica desenvolvida pela comunidade soberiana nessa área, ao longo de 2004 a 2013.

A análise permite deduzir, de um modo geral, que esforços científicos em torno da temática da ação coletiva no setor agroindustrial vêm aumentando. $\mathrm{O}$ interesse dos pesquisadores foi observado, pois há um número significativo de produções nesse contexto. Isso desperta ainda mais a atenção, dado o leque de temáticas possíveis no âmbito rural brasileiro, num escopo interdisciplinar entre a economia, administração e sociologia. Acredita-se que esse resultado positivo seja em decorrência do alto índice de trabalhos em regime de coautoria e, ainda, sob a perspectiva interinstitucional, aspectos esses ajustados à tendência colaborativa da pesquisa global.

Contudo, o aspecto teórico ainda merece um olhar mais atento da comunidade científica. Um alto índice de trabalhos demonstrou fragilidade nesse quesito, uma vez que, muitas vezes, não trazem os fundamentos da teoria e das abordagens teóricas da ação coletiva, apresentando, principalmente, resultados empíricos. Dessa forma, apontam para estudos de ordem mais técnica e por vezes com pouca reflexão teórica. Sabe-se que a teoria da ação coletiva ainda é recente, mas acredita-se também que o corpus teórico já existente seja satisfatório para embasar as pesquisas de campo realizadas.

Evidenciou-se, também, que os sistemas agroindustriais mais estruturados e com maior taxa de formalização, como o caso das cooperativas no segmento 
leiteiro, foram os mais escolhidos pelos autores da área para o desenvolvimento de seus estudos. Todavia, entende-se que segmentos menos estruturados também podem representar importantes objetos de investigação para a ação coletiva.

Por fim, ressalta-se, que, neste estudo, o objeto de investigação se limitou aos estudos desenvolvidos em dez congressos da Sober, não congregando outras formas de publicação. Assim, para trabalhos futuros, sugerem-se estudos que incorporem em suas análises, periódicos científicos das três áreas em questão, bem como a análise de ações coletivas em outros setores da economia. Quanto aos estudos já existentes, a investigação teórica representaria um avanço para o diálogo.

\section{REFERÊNCIAS}

AUSTIN, J. E. Parcerias. São Paulo: Futura, 2001.

BRITO, C. M. Towards an institutional theory of the dynamics of industrial networks. Journal of Business \& Industrial Marketing. v. 16, n. 3, p. 150-166, 2001.

BULGACOV, S.; VERDU, F. C. Redes de Pesquisadores da Área de Administração: um Estudo Exploratório. Revista de Administração Contemporânea - RAC, edição especial, p. 163-182, 2001.

ECONOMIDES, N. The Economics of Networks. International Journal of Industrial Organization, v. 14, p. 673-699, 1996.

GRANDORI, A.; SODA, G. Inter-firm networks: antecedents, mechanisms and forms. Organization Studies. v. 6, n. 2, p. 183-214, 1995.

HARDIN, R. One for All: The Logic of Group Conflict. Princeton: Princeton University Press, 1997.

LAZZARINI, S.G.; CHADDAD, F.R.; COOK, M. L. Integrating Supply Chain and Network Analysis: The study of netchains. Journal of Chain and Network Science, 2001.

MACIAS-CHAPULA, C. A. O papel da informetria e da cienciometria e sua perspectiva nacional e internacional. Ciência da informação, v. 27, n. 2, p. 134-140, 1998. 
MAEDA, M. Y.; SAES, M. S. M. A lógica da ação coletiva: a experiência do Condomínio Agrícola Leópolis. In: XII SEMEAD-Seminários em Administração, 2009, São Paulo. XII SEMEAD - Empreendedorismo e Inovação, 2009.

MÉNARD, C. The economics of hybrid Organizations. Journal of Instituonal and Theoretical Economics. v. 160, n. 3, p. 345-376, 2004.

MÉNARD, C.; KLEIN, P. G. Organizational issues in the agrifood sector: toward a comparative approach. American Journal of Agricultural Economics, 2004 86(3): 750-755.

OLSON, M. A lógica da ação coletiva: os benefícios públicos e uma teoria dos grupos sociais. São Paulo: Editora da Universidade de São Paulo, 1999.

PINHO, D. B. A doutrina cooperativa nos regimes capitalista e socialista. 2 ed. São Paulo: Pioneira, 1996.

PORTER, M. Competição: estratégias competitivas essenciais. Rio de Janeiro: Campus, 1999.

REDESIT. Rede de Pesquisa em Sistemas e Arranjos Produtivos e Inovativos Locais. 2014. Foco. Disponível em: < http://www.redesist.ie.ufrj.br/>. Acesso em: 03 abr 2014.

SACHS, I. Inclusão social pelo trabalho: desenvolvimento humano, trabalho descente e futuro dos empreendedores de pequeno porte. Rio de Janeiro: Garamond, 2003.

SAES, M. S. M. Estratégias de diferenciação e apropriação da quase-renda na agricultura: a produção de pequena escala. São Paulo, 2008. Tese (Livre Docência em Administração) - Programa de Pós Graduação em Administração, Departamento de Administração da Faculdade de Economia, Administração e Contabilidade de São Paulo.

SAUVÉE, L. Efficiency, effectiveness and the design of network governance. $5^{\text {th }}$ International Conference on Chain Management in Agribusiness and the food industry. The Netherlands, june, 2002. 
SCHMIDT, C. M. Criação e apropriação de valor no sistema agroindustrial do vinho do Vale dos Vinhedos. São Paulo, 2010. Tese (Doutorado) - Faculdade de Economia, Administração e Contabilidade. Universidade de São Paulo.

SCHMIDT, C. M.; SAES, M. S. M. Ações coletivas: desenvolvimento para arranjos produtivos inseridos no contexto do agronegócio e turismo rural. In: $46^{\circ}$ Congresso da Sociedade Brasileira de Economia, Administração e Sociologia Rural, 2008, Rio Branco, Anais... Rio Branco, 2008.

SILVA NETO, P. Q. et al. Cooperativismo como organismo equalizador da renda. In: $1^{\circ}$ Encontro de Estudos sobre Empreendedorismo e Gestão de Pequenas Empresas, 2000, Maringá, Anais... Maringá, 2013.

VANTI, N. A. P. (2002). Da bibliometria à webometria: uma exploração conceitual dos mecanismos utilizados para medir o registro da informação e a difusão do conhecimento. Ciência da Informação, v. 31, n. 2, p. 152-162, 2002.

ZYLBERSZTAJN, D.; FARINA, E. Strictly Coordinated Food-Systems: exploring the limits of the Coasian Firm. International Food and Agribusiness Management Review, v. 2, n. 2, p. 249-265, 1999.

ZYLBERSZTAJN, D.; FARINA, E. Dynamics of network governance: a contribuition to the study of complex forms. Série Working Paper n. 03/026, São Paulo, 2006. Disponível em: <http://www.ead.fea.usp.br/WPapers/2003/03-026.pdf> Acesso em: 01 Ago 2013.

ZYLBERSZTAJN, D. From Contracts to Networks: New Directions in the Study of Governance of Agro-Food-Energy Networks. In: $4^{\mathrm{TH}}$ EUROPEAN FORUM ON SYSTEMS DYNAMICS AND INNOVATION IN FOOD NETWORKS, 2010, InnsbruckIgls, Anais... Innsbruck-Igls, 2010.

Recebido em: 2014-10-08 Aceito em: 2017-03-02 